\title{
Penerapan Metode PIECES Framework Dalam Analisis dan Evaluasi Aplikasi M-BCA
}

\author{
Randi Prayogi ${ }^{1}$, Kresna Ramanda ${ }^{2}$, Cahyani Budihartanti ${ }^{3}$, Arief Rusman ${ }^{4}$ \\ 1,2,3,4 Sekolah Tinggi Manajemen Informatika \& Komputer Nusa Mandiri \\ e-mail: $\underline{1}$ randyprayogi41@gmail.com,${ }^{2}$ kresna.kra@ nusamandiri.ac.id,$\underline{ }{ }^{3}$ cahyani.cbh@nusamandiri.ac.id, \\ arief.aef@nusamandiri.ac.id
}

\begin{tabular}{ccc}
\hline Diterima & Direvisi & Disetujui \\
$14-02-2021$ & $10-03-2021$ & $15-03-2021$ \\
\hline
\end{tabular}

\begin{abstract}
Abstrak - Mobile BCA atau yang biasa di sebut M-BCA, merupakan sebuah aplikasi perbankan diperuntukan kepada semua nasabah BCA yang memiliki tabungan, namun M-BCA tidak diperuntukan kepada nasabah TabunganKu, karena tahapan tersebut hanya diperuntukan bagi anak-anak. Aplikasi M-BCA dapat diinstal pada smartphone, seperti Android dan IOS. Cukup dengan terhubung internet dan mengakses M-BCA, maka seluruh urusan perbankan selesai dalam hitungan menit.Ada banyak menu yang disediakan pada aplikasi M-BCA seperti m-info, BagiBagi, Flazz, m-Info, m-Transfer, m-Payment, m-Commerce, Cardless (khusus OS Android dan IOS), QR, m-Admin, Aktivasi BCA Keyboard. Dengan adanya aplikasi M-BCA perlu dilakukan identifikasi masalah untuk mengetahui seberapa puas pengguna terhadap aplikasi M-BCA. Salah satu metode yang bisa digunakan untuk mengevaluasinya adalah dengan menggunakan metode PIECES (Performance, Information, Economic, Control, Efficiency, Service). Berdasarkan metode PIECES yang terdiri dari Performance, Information, Economics, Control, Efficiency dan Service dalam mengukur tingkat kepuasan terhadap pengguna aplikasi mBCA dapat dilihat tingkat kepuasan pengguna dari masing-masing domain, dimana Performance memperoleh nilai 4.23, Information memperoleh nilai 4.44, Economy memperoleh nilai 4.60, Control memperoleh nilai 4.59, Efficiency memperoleh nilai 4.62, dan Service memperoleh nilai 4.65. Karena masing-masing nilai berada di 3.4 - 4.91, yang berarti pengguna merasa PUAS terhadap aplikasi m-BCA.
\end{abstract}

Kata Kunci: Kepuasan pengguna, Aplikasi M-BCA, PIECES

\begin{abstract}
Mobile BCA or commonly referred to as $M-B C A$, is a banking application intended for all BCA customers who have savings, however M-BCA is not intended for TabunganKu customers, because this stage is only for children. The M-BCA application can be installed on smartphones, such as Android and IOS. Simply by connecting to the internet and accessing $M-B C A$, all banking matters are completed in minutes. There are many menus provided in the M-BCA application such as m-info, BagiBagi, Flazz, m-Info, $m$-Transfer, $m$-Payment, $m$ Commerce, Cardless (for Android and IOS OS only), QR, m-Admin, BCA Keyboard activation. With the M-BCA application, it is necessary to identify problems to find out how satisfied users are with the M-BCA application. One method that can be used to evaluate it is by using the PIECES method (Performance, Information, Economic, Control, Efficiency, Service). Based on the PIECES method which consists of Performance, Information, Economics, Control, Efficiency and Service in measuring the level of satisfaction with users of the m-BCA application, it can be seen that the level of user satisfaction from each domain, where Performance gets a score of 4.23, Information gets a value of 4.44, Economy got a score of 4.60, Control got a score of 4.59, Efficiency got a score of 4.62, and Service got a score of 4.65. Because each value is at $3.4-4.91$, which means that users feel SATISFIED with the $m$-BCA application.
\end{abstract}

Keywords: User satisfaction, $M-B C A$ application, PIECES

\section{PENDAHULUAN}

Berbagai cara juga dilakukan oleh perusahaan agar dapat bertahan di dunia usaha yang penuh persaingan ini. Seperti hal nya Bank Central Asia (BCA) yang selalu mengikuti trend terbaru untuk meningkatkan pelayanan kepada para nasabah. Salah satu pelayanan yang diberikan BCA kepada nasabah adalah dengan mengeluarkan sebuah aplikasi mobile banking BCA yang biasa sering disebut M-BCA. MBCA dapat diperuntukan kepada semua nasabah BCA yang memiliki tabungan, namun M-BCA tidak diperuntukan kepada nasabah tahapan tabunganku, karena tahapan tersebut hanya diperuntukan bagi anak-anak. Aplikasi M-BCA dapat diinstal pada smartphone, seperti Android, IOS dan Blackberry. Cukup dengan terhubung internet dan mengakses M$\mathrm{BCA}$, maka seluruh urusan perbankan selesai dalam 
hitungan menit.Ada banyak menu yang disediakan pada aplikasi M-BCA seperti m-info, BagiBagi, Flazz, m-Info, m-Transfer, m-Payment, m-Commerce, Cardless (khusus OS Android dan IOS), QR, mAdmin, Aktivasi BCA Keyboard ("BCAMobile," n.d.).

Dengan adanya aplikasi M-BCA perlu dilakukan identifikasi masalah untuk mengetahui seberapa puas pengguna terhadap aplikasi M-BCA. Salah satu metode yang bisa digunakan untuk mengevaluasinya adalah dengan menggunakan metode PIECES (Performance, Information, Economic, Control, Effisiency, Service) (Muliansah \& Budihartanti, 2020). Dengan melakukan pendekatan melakukan pendekatan menggunakan metode analisis PIECES, diharapkan dapat memberikan penilaian secara menyeluruh tentang penerapan system yang digunakan, dan hasil yang didapatkan dari analisis ini diharapkan dapat menjadi acuan untuk terus mengembangkan system untuk kemajuan yang lebih baik lagi (Dwiyantoro, 2019).

Pada penelitian yang dilakukan oleh (Agustina, 2018), Evaluasi Penggunaan system informasi ERP dengan menggunakan metode Pieces Framework, semuanya berada posisi BAIK dengan hasil ini artinya penerapan system informasi ERP dilingkungan perusahaan khususnya yang digunakan oleh bagian akuntansi dan keuangan serta marketing sales berdasarkan erangka PIECES sudah dapat diterima oleh dua bagian tersebut sebagai pengguna dari system informasi ERP. Pada penelitian yang dilakukan oleh Wijaya, mengemukakan bahwa hasil pengukuran performance dapat disimpulkan bahwa website KPM dalam kecepatan loading time sudah termasuk kategori baik yaitu dengnan didapatkannya grade $\mathrm{B}$. Hanya saja masih terdapat kekurangan dalam performa yang dihasilkan, yaitu pada combine images using CSS sprites dan optimize images yang mendapatkan grade F (Wijaya, 2018). Sedangkan pada penelitian (Muliansah \& Budihartanti, 2020) dengan menggunakan analisa metode PIECES dapat diketahui bagaimanakah kepuasan petugas dalam menggunakan e-Puskesmas di loket pandaftaran berdasarkan indicator Performance, Information, Economy, Control, Efficiency dan Service. Berdasarkan latar belakang tersebut, maka peneliti mengangkat judul "Penerapan Metode PIECES (Performance, Information, Economy, Control, Efficiency and Service) Kepada Pengguna Aplikasi MBCA".

\section{METODE PENELITIAN}

PIECES framework adalah sebuah metode yang digunakan untuk mengklasifikasikan suatu problem, opportunities, dan directives yang terdapat pada bagian scope definition, analisis dan perancangan sistem. Dengan menggunakan metode ini dapat dihasilkan hal-hal baru yang dapat dijadikan pertimbangan dalam pengembangan sistem. Dalam PIECES terdapat enam variabel yang digunakan untuk menganalisis sistem informasi, yaitu (Kristy \& Kusuma, 2018):

\section{Performance (Keandalan)}

Variable ini digunakan untuk mengetahui kinerja sebuah sistem, apakah berjalan dengan baik atau tidak. Kinerja ini dapat diukur dari jumlah temuan data yang dihasilkan dan seberapa cepat suatu data dapat ditemukan.

2. Information and Data (Data dan Informasi)

Dalam sebuah temuan data pasti akan dihasilkan sebuah informasi yang akan ditampilkan,variable ini digunakan untuk menganalisis seberapa banyak dan seberapa jelas informasi yang akan dihasilkan untuk satu pencarian.

\section{Economics (Nilai Ekonomis)}

Variabel ini digunakan untuk melakukan analisis pada sistem, untuk mengetahui apakah suatu sistem tersebut tepat diterapkan pada suatu lembaga informasi dilihat dari segi finansial dan biaya yang dikeluarkan. Hal ini sangat penting Karena suatu sistem juga dipengaruhi oleh besarnya biaya yang dikeluarkan.

4. Control and security (Pengendalian dan Pengamanan)

Dalam suatu sistem perlu diadakan sebuahcontrol atau pengawasan agar sistem itu berjalan dengan baik. Analisis ini digunakanuntuk mengetahui sejauh mana pengawasan dan kontrol yang dilakukan agar sistem tersebut berjalan dengan baik.

\section{Efficiency (Efisiensi)}

Efisiensi dan efektivitas sebuah sistem perlu dipertanyakan dalam kinerja dan alas an mengapa sistem itu dibuat. Sebuah sistem harus bisa secara efisien menjawab dan membantu suatu permasalahan khususnya dalam hal otomasi. Analisis ini dilakukan untuk mengetahui apakah suatu sistem itu efisien atau tidak, dengan input yang sedikit bias menghasilkan sebuah output yang memuaskan.

\section{Service (Pelayanan)}

Dalam hal Pemanfaat suatu system sebuah pelayanan masih menjadi suatu hal yang penting dan perlu diperhatikan. Suatu sistem yang diterapkan akan berjalan dengan baik 
danseimbang bila diimbangi dengan pelayanan yang baik juga. Analisis ini digunakan untuk mengetahui bagaimana pelayanan yang dilakukan dan mengetahui permasalahan permasalahan yang ada terkait tentang pelayanan

Hasil penilaian kuesioner terhadap pengguna aplikasi dalam mengukur kualitas pelayanan terhadap kepuasan konsumen menggunakan skala likert. Untuk mendapatkan rata-rata tingkat kepuasan dengan menggunakan rumus (Muliansah \& Budihartanti, 2020)(Asbar \& Saptari, 2017):

$$
R K=\frac{J S K}{J K}(1)
$$

RK = Rata-rata kepuasan

JSK = Jumlah Skor Kuesioner

$\mathrm{JK}=$ Jumlah kuesioner

Untuk menentukan tingkat kepuasan menggunakan model yang didefinisikan oleh Kaplan dan Norton dengan tingkatan sebagai berikut (Asbar \& Saptari, 2017) :

$$
\begin{array}{ll}
1-1.79 & =\text { Sangat tidak Puas } \\
1.8-2.59 & =\text { Tidak Puas } \\
2.6-3.39 & =\text { Ragu-ragu } \\
3.4-4.91 & =\text { Puas } \\
4.92-5 & =\text { Sangat Puas }
\end{array}
$$

\section{HASIL DAN PEMBAHASAN}

Berdasarkan hasil penilaian kuisioner terhadap pengguna aplikasi analisa dalam mengukur kualitas pelayanan terhadap kepuasan pengguna dengan menggunakan skala Likert untuk mengetahui tingkat kepuasan pengguna mobile-BCA (m-BCA). Adapun hasil pengolahan kuesioner dalam melihat tingkat kepuasan pelanggan adalah sebagai berikut:

1. Indikator Performance

\begin{tabular}{|c|c|c|c|c|}
\hline 4 & 4 & 4 & 3 & 4 \\
\hline 5 & 4 & 4 & 4 & 5 \\
\hline 6 & 5 & 4 & 5 & 5 \\
\hline 7 & 5 & 5 & 4 & 5 \\
\hline 8 & 5 & 4 & 4 & 5 \\
\hline 9 & 4 & 4 & 4 & 5 \\
\hline 10 & 4 & 4 & 4 & 5 \\
\hline 11 & 4 & 5 & 4 & 5 \\
\hline 12 & 4 & 4 & 4 & 5 \\
\hline 13 & 4 & 5 & 4 & 4 \\
\hline 14 & 4 & 4 & 4 & 4 \\
\hline 15 & 5 & 4 & 5 & 5 \\
\hline 16 & 4 & 4 & 4 & 4 \\
\hline 17 & 4 & 4 & 4 & 5 \\
\hline 18 & 4 & 4 & 4 & 4 \\
\hline 19 & 4 & 3 & 4 & 4 \\
\hline 20 & 5 & 4 & 4 & 5 \\
\hline 21 & 4 & 3 & 5 & 4 \\
\hline 22 & 5 & 4 & 4 & 5 \\
\hline 23 & 4 & 5 & 4 & 4 \\
\hline 24 & 5 & 4 & 4 & 4 \\
\hline 25 & 4 & 4 & 3 & 4 \\
\hline 26 & 4 & 4 & 4 & 4 \\
\hline 27 & 4 & 4 & 4 & 4 \\
\hline 28 & 3 & 3 & 3 & 3 \\
\hline 29 & 5 & 4 & 5 & 5 \\
\hline 30 & 5 & 4 & 4 & 4 \\
\hline $\begin{array}{c}\text { Rata - } \\
\text { Rata }\end{array}$ & 4.3 & 4.1 & 4.1 & 4.47 \\
\hline
\end{tabular}

Hasil pengolahan indikator performance dapat dilihat pada tabel 1

Tabel 1 Hasil pengolahan kuesioner Indikator Performance

\begin{tabular}{ccccc}
\hline \multirow{2}{*}{$\begin{array}{c}\text { No } \\
\text { Responden }\end{array}$} & \multicolumn{4}{c}{ Indikator } \\
\cline { 2 - 5 } & P1 & P2 & P3 & P4 \\
\hline 1 & 4 & 4 & 4 & 5 \\
2 & 5 & 4 & 4 & 4 \\
3 & 5 & 5 & 5 & 5
\end{tabular}

Sumber : Olah Data (2020)

$$
\begin{aligned}
& R K=\frac{4,33+4,07+4,07+4,47}{4} \\
& R K=\frac{16,93}{4} \\
& R K=4,23
\end{aligned}
$$

Berdasarkan hasil perhitungan jumlah ratarata tingkat kepuasan diperoleh bernilai 4.23 pada domain Performance. Kepuasan pengguna terhadap aplikasi $m$ - $b c a$ termasuk dalam kategori PUAS. Sehingga hal ini menunjukkan indikasi yang positif yaitu pengguna sudah merasa puas dengan Performance dari aplikasi $m$-bca.

\section{Indikator Information}

Hasil pengolahan indiator informasi, dapat dilihat pada tabel 2

Tabel 2 Hasil pengolahan kuesioner Indikator Information

\begin{tabular}{ccccc}
\hline No & \multicolumn{4}{c}{ Indikator Information } \\
\cline { 2 - 5 } Responden & I1 & I2 & I3 & I4 \\
\hline 1 & 5 & 4 & 4 & 5 \\
2 & 5 & 5 & 5 & 4 \\
3 & 5 & 5 & 5 & 5 \\
4 & 4 & 4 & 5 & 4
\end{tabular}




\begin{tabular}{ccccc}
5 & 5 & 5 & 4 & 5 \\
6 & 5 & 4 & 5 & 5 \\
7 & 5 & 5 & 5 & 5 \\
8 & 5 & 4 & 4 & 5 \\
9 & 5 & 5 & 4 & 5 \\
10 & 5 & 5 & 4 & 5 \\
11 & 4 & 5 & 5 & 5 \\
12 & 5 & 5 & 4 & 5 \\
13 & 4 & 5 & 4 & 4 \\
14 & 5 & 5 & 4 & 4 \\
15 & 5 & 4 & 5 & 5 \\
16 & 4 & 4 & 4 & 4 \\
17 & 5 & 5 & 4 & 5 \\
18 & 4 & 4 & 4 & 4 \\
19 & 4 & 4 & 4 & 4 \\
20 & 5 & 4 & 4 & 5 \\
21 & 4 & 3 & 5 & 4 \\
22 & 5 & 5 & 4 & 5 \\
23 & 4 & 5 & 4 & 4 \\
24 & 5 & 5 & 4 & 4 \\
25 & 5 & 4 & 3 & 4 \\
26 & 4 & 4 & 4 & 4 \\
27 & 4 & 5 & 4 & 4 \\
28 & 3 & 4 & 3 & 3 \\
29 & 5 & 4 & 5 & 5 \\
30 & 5 & 4 & 4 & 4 \\
\hline Rata & 4.6 & 4.4667 & 4.2333 & 4.467 \\
Rata & & & \\
\hline Sum $: 019 h$ & $0 a$ & 2020 & &
\end{tabular}

Sumber : Olah Data (2020)

$R K=\frac{4,6+4,47+4,23+4,47}{4}$

$R K=\frac{17,77}{4}$

$R K=4,44$

Berdasarkan hasil perhitungan jumlah ratarata tingkat kepuasan diperoleh bernilai 4.44 pada domain Information. Kepuasan pengguna terhadap aplikasi $m$ - $b c a$ termasuk dalam kategori PUAS. Sehingga hal ini menunjukkan indikasi yang positif yaitu pengguna sudah merasa puas dengan Information dari aplikasi $m-b c a$.

3. Indikator Economy

Hasil pengolahan data indicator economy, dapat dilihat pada tabel 3

Tabel 3 Hasil pengolahan kuesioner Indikator

\begin{tabular}{ccccc}
\multicolumn{5}{c}{ Economy } \\
\hline No & \multicolumn{3}{c}{ Indikator Economy } \\
\cline { 2 - 5 } Responden & E1 & E2 & E3 & E4 \\
\hline 1 & 5 & 5 & 5 & 5 \\
2 & 5 & 5 & 4 & 4 \\
3 & 5 & 5 & 5 & 5 \\
4 & 5 & 5 & 5 & 4 \\
5 & 5 & 5 & 4 & 5
\end{tabular}

\begin{tabular}{ccccc}
6 & 5 & 4 & 5 & 5 \\
7 & 5 & 5 & 5 & 5 \\
8 & 5 & 4 & 4 & 5 \\
9 & 5 & 5 & 5 & 5 \\
10 & 5 & 5 & 5 & 5 \\
11 & 4 & 5 & 5 & 5 \\
12 & 5 & 5 & 4 & 5 \\
13 & 5 & 5 & 4 & 5 \\
14 & 5 & 5 & 5 & 5 \\
15 & 5 & 4 & 5 & 5 \\
16 & 5 & 5 & 5 & 4 \\
17 & 5 & 5 & 5 & 5 \\
18 & 4 & 4 & 4 & 4 \\
19 & 4 & 4 & 5 & 4 \\
20 & 5 & 4 & 5 & 5 \\
21 & 4 & 4 & 5 & 4 \\
22 & 5 & 5 & 4 & 5 \\
23 & 4 & 5 & 4 & 4 \\
24 & 5 & 5 & 4 & 4 \\
25 & 5 & 4 & 5 & 4 \\
26 & 5 & 5 & 4 & 4 \\
27 & 4 & 5 & 4 & 4 \\
28 & 3 & 3 & 3 & 3 \\
29 & 5 & 4 & 5 & 5 \\
30 & 5 & 4 & 4 & 4 \\
\hline Rata - & 4.733 & 4.6 & 4.533 & 4.533 \\
Rata & & & & \\
\hline O1ah Data & $(2020)$ & &
\end{tabular}

Sumber : Olah Data (2020)

$R K=\frac{4,73+4,60+4,53+4,53}{4}$

$R K=\frac{18,4}{4}$

$R K=4,6$

Berdasarkan hasil perhitungan jumlah rata-rata tingkat kepuasan diperoleh bernilai 4.6 pada domain Economy. Kepuasan pengguna terhadap aplikasi $m-b c a$ termasuk dalam kategori PUAS. Sehingga hal ini menunjukkan indikasi yang positif yaitu pengguna sudah merasa puas dengan Economy dari aplikasi $m-b c a$.

4. Indikator Control

Hasil pengolahan data indikator control dapat dilihat pada tabel 4

Tabel 4 Hasil pengolahan kuesioner Indikator

\begin{tabular}{ccccc}
\multicolumn{5}{c}{ Control } \\
\hline No & \multicolumn{3}{c}{ Indikator Control } \\
\cline { 2 - 5 } Responden & C1 & C2 & C3 & C4 \\
\hline 1 & 5 & 5 & 5 & 5 \\
2 & 5 & 5 & 4 & 3 \\
3 & 5 & 5 & 5 & 5 \\
4 & 5 & 5 & 5 & 4 \\
5 & 5 & 5 & 4 & 5 \\
6 & 5 & 4 & 5 & 5 \\
7 & 5 & 5 & 5 & 5 \\
8 & 5 & 5 & 4 & 5
\end{tabular}




\begin{tabular}{ccccc}
9 & 5 & 5 & 5 & 5 \\
10 & 5 & 5 & 5 & 5 \\
11 & 4 & 5 & 5 & 5 \\
12 & 5 & 5 & 4 & 5 \\
13 & 5 & 5 & 4 & 5 \\
14 & 5 & 5 & 5 & 5 \\
15 & 5 & 4 & 5 & 5 \\
16 & 5 & 5 & 5 & 4 \\
17 & 5 & 5 & 5 & 4 \\
18 & 4 & 4 & 4 & 4 \\
19 & 4 & 4 & 5 & 4 \\
20 & 5 & 4 & 5 & 5 \\
21 & 4 & 4 & 5 & 4 \\
22 & 5 & 5 & 4 & 5 \\
23 & 4 & 5 & 4 & 4 \\
24 & 5 & 5 & 4 & 4 \\
25 & 5 & 4 & 5 & 4 \\
26 & 5 & 5 & 4 & 4 \\
27 & 4 & 5 & 4 & 4 \\
28 & 3 & 3 & 3 & 3 \\
29 & 5 & 4 & 5 & 5 \\
30 & 5 & 4 & 4 & 4 \\
\hline Rata - & 4.73 & 4.63 & 4.53 & 4.47 \\
Rata & & & & \\
\hline O1ah Dat & $(2020)$ & & &
\end{tabular}

Sumber : Olah Data (2020)

$R K=\frac{4,73+4,63+4,53+4,47}{4}$

$R K=\frac{18,37}{4}$

$R K=4,59$

Berdasarkan hasil perhitungan jumlah rata- rata tingkat kepuasan diperoleh bernilai 4.59 pada domain Control. Kepuasan pengguna terhadap aplikasi $m-b c a$ termasuk dalam kategori PUAS. Sehingga hal ini menunjukkan indikasi yang positif yaitu pengguna sudah merasa puas dengan Control dari aplikasi $m$ bca.

5. Indikator Efficiency

Hasil pengolahan data indikator efficiency dapat dilihat pada tabel 5 .

Tabel 5 Hasil pengolahan kuesioner Indikator Efficiency

\begin{tabular}{ccccc}
\hline \multirow{2}{*}{$\begin{array}{c}\text { No } \\
\text { Responden }\end{array}$} & \multicolumn{4}{c}{ Indikator Efficiency } \\
\cline { 2 - 5 } & EF1 & EF2 & EF3 & EF4 \\
\hline 1 & 5 & 5 & 5 & 5 \\
2 & 5 & 5 & 4 & 3 \\
3 & 5 & 5 & 5 & 5 \\
4 & 5 & 5 & 5 & 4 \\
5 & 5 & 5 & 4 & 4 \\
6 & 5 & 4 & 5 & 5 \\
7 & 5 & 5 & 5 & 5 \\
8 & 5 & 5 & 4 & 5 \\
9 & 5 & 5 & 5 & 5 \\
10 & 5 & 5 & 5 & 5 \\
11 & 4 & 5 & 5 & 5
\end{tabular}

\begin{tabular}{ccccc}
12 & 5 & 5 & 5 & 5 \\
13 & 5 & 5 & 5 & 5 \\
14 & 5 & 5 & 5 & 5 \\
15 & 5 & 4 & 5 & 5 \\
16 & 5 & 5 & 5 & 4 \\
17 & 5 & 5 & 5 & 4 \\
18 & 5 & 4 & 4 & 4 \\
19 & 5 & 4 & 5 & 4 \\
20 & 5 & 4 & 5 & 5 \\
21 & 4 & 4 & 5 & 4 \\
22 & 5 & 5 & 4 & 5 \\
23 & 4 & 5 & 4 & 4 \\
24 & 5 & 5 & 4 & 4 \\
25 & 5 & 4 & 5 & 4 \\
26 & 5 & 5 & 4 & 4 \\
27 & 4 & 5 & 4 & 4 \\
28 & 3 & 3 & 3 & 3 \\
29 & 5 & 4 & 5 & 5 \\
30 & 5 & 4 & 4 & 4 \\
\hline Rata - & 4.8 & 4.63 & 4.6 & 4.43 \\
Rata & & &
\end{tabular}

Sumber : Olah Data (2020)

$R K=\frac{4,8+4,63+4,6+4,43}{4}$

$R K=\frac{18,47}{4}$

$R K=4,62$

Berdasarkan hasil perhitungan jumlah rata- rata tingkat kepuasan diperoleh bernilai 4.62 pada domain Efficiency. Kepuasan pengguna terhadap aplikasi $m$ bca termasuk dalam kategori PUAS. Sehingga hal ini menunjukkan indikasi yang positif yaitu pengguna sudah merasa puas dengan Efficiency dari aplikasi $m$ bca.

6. Indikator Service

Hasil pengolahan data pada indicator service, dapat dilihat pada tabel 6

Tabel 6 Hasil pengolahan kuesioner Indikator Service

\begin{tabular}{ccccc}
\hline \multirow{2}{*}{$\begin{array}{c}\text { No } \\
\text { Responden }\end{array}$} & \multicolumn{4}{c}{ Indikator Service } \\
\cline { 2 - 5 } & S1 & S2 & S3 & S4 \\
\hline 1 & 5 & 5 & 5 & 5 \\
2 & 5 & 5 & 4 & 4 \\
3 & 5 & 5 & 5 & 5 \\
4 & 5 & 5 & 5 & 4 \\
5 & 5 & 4 & 5 & 4 \\
6 & 5 & 4 & 5 & 5 \\
7 & 5 & 5 & 5 & 5 \\
8 & 5 & 5 & 5 & 5 \\
9 & 5 & 5 & 5 & 5 \\
10 & 5 & 5 & 5 & 5 \\
11 & 4 & 5 & 5 & 5 \\
12 & 5 & 5 & 5 & 5 \\
13 & 5 & 5 & 5 & 5 \\
14 & 5 & 5 & 5 & 5
\end{tabular}




$\begin{array}{rrr}15 & 5 & 4 \\ 16 & 5 & 5 \\ 17 & 5 & 5 \\ 18 & 5 & 4 \\ 19 & 5 & 4 \\ 20 & 5 & 4 \\ 21 & 4 & 4 \\ 22 & 5 & 5 \\ 23 & 4 & 5 \\ 24 & 5 & 5 \\ 25 & 5 & 4 \\ 26 & 5 & 5 \\ 27 & 4 & 5 \\ 28 & 4 & 3 \\ 29 & 5 & 4 \\ 30 & 5 & 4 \\ \text { Sumber }: \text { Olah Data }(2020) & \\ \text { Rata }- & 4.83 & 4.6 \\ R K=\frac{4,83+4,6+4,7+4,47}{4,65} & \\ R K=\frac{4}{4} & \end{array}$

Berdasarkan hasil perhitungan jumlah ratarata tingkat kepuasan diperoleh bernilai 4.65 pada domain Service. Kepuasan pengguna terhadap aplikasi $m$ - $b c a$ termasuk dalam kategori PUAS. Sehingga hal ini menunjukkan indikasi yang positif yaitu pengguna sudah merasa puas dengan Service dari aplikasi $m$-bca.

Tabel 7 Hasil Rekapitulasi Indikator

\begin{tabular}{|c|c|}
\hline Indikator & Nilai \\
\hline Performance & 4.23 \\
\hline Information & 4.44 \\
\hline Economy & 4.60 \\
\hline Control & 4.59 \\
\hline Efficiency & 4.62 \\
\hline Service & 4.65 \\
\hline Jumlah Rata - Rata & 4.52 \\
\hline
\end{tabular}

Sumber : Olah Data (2020)

Berdasarkan hasil perhintungan pada setiap indikator Performance, Information, Economy, Control, Efficiency, Service mendapatkan jumlah ratarata tingkat kepuasan diperoleh nilai 4.52 , maka dapat disimpulkan bahwa tingkat kepuasan pengguna terhadap aplikasi $m$-bca termasuk dalam kategori PUAS. Sehingga hal ini menunjukkan indikasi yang positif yaitu pengguna sudah merasa puas dengan adanya pelayanan aplikasi $m-b c a$.

\section{.KESIMPULAN}

Berdasarkan metode PIECES yang terdiri dari Performance, Information, Economics, Control, Efficiency dan Service dalam mengukur tingkat kepuasan terhadap pengguna aplikasi $m-B C A$ dapat dilihat tingkat kepuasan pengguna dari masingmasing domain, dimana Performance memperoleh nilai 4.23, Information memperoleh nilai 4.44, Economy memperoleh nilai 4.60, Control memperoleh nilai 4.59, Efficiency memperoleh nilai 4.62, dan Service memperoleh nilai 4.65. Karena masing-masing nilai berada di 3.4 - 4.91, yang berarti pengguna merasa PUAS terhadap aplikasi $m-B C A$.

Dari kelima kerangka kerja pada metode PIECES, indicator Performance pada butir P3 mendapatkan nilai terendah, yang berarti harus ada perbaikan pada "Menu-menu yang tersedia secara instan agar dapat memunculkan informasi sesuai dengan kebutuhan perbankan". Diharapkan penelitian berikutnya menambah indikator lain yang dapat membuat hasil penelitian menjadi lebih baik lagi.

\section{REFERENSI}

Agustina, N. (2018). Evaluasi Penggunaan Sistem Informasi ERP Dengan Metode Pieces Framework. Jurnal Informatika, 5(2), 278-286. https://doi.org/10.31311/ji.v5i2.3897

Asbar, Y., \& Saptari, M. A. (2017). Analisa Dalam Mengukur Kualitas Pelayanan Terhadap Kepuasan Konsumen Menggunakan Metode PIECES. Jurnal Visioner \& Strategis, 6(2), 3947.

BCAMobile. (n.d.).

Dwiyantoro, D. (2019). Analisis dan Evaluasi Penerapan Sistem Informasi Smart Library AMIKOM Resource Centre dengan Metode Pieces Framework. Tik Ilmeu: Jurnal Ilmu Perpustakaan Dan Informasi, 3(2), 109-124. https://doi.org/10.29240/tik.v3i2.962

Kristy, R. D., \& Kusuma, W. A. (2018). Analisi Tingkat Kepuasan dan Tingkat Kepentingan Penerapan Sistem Informasi Universitas Muhammadiyah Malang. Teknika : Engineering and Sains Journal, 2(1), 17-24. https://doi.org/10.5422/fordham/978082323150 8.003.0003

Muliansah, R., \& Budihartanti, C. (2020). Analisa Pemanfaatan e-Puskesmas di Loket Pendaftaran pada Puskesmas Kecamatan Pademangan dengan Metode PIECES. Journal of Computer Science and Engineering (JCSE), 1(1), 17-29. https://doi.org/10.36596/jcse.v1i1.22

Wijaya, H. O. L. (2018). Implementasi Metode PIECES Pada Analisis Website Kantor Penanaman Modal Kota Lubuklinggau. JUSIM (Jurnal Sistem Informasi Musirawas), 3(1), 4858. https://doi.org/10.32767/jusim.v3i1.289 